\title{
Effect of oxygen supplementation in a hatchery at high altitude and growth performance of broilers reared at low altitude
}

\author{
B. Yılmaz-Dikmen ${ }^{1 \#}$, Ü. Şahan ${ }^{1}$, A. İpek ${ }^{1}$, C. Aydın² \& E. Kederli ${ }^{3}$ \\ ${ }^{1}$ Department of Animal Science, Faculty of Agriculture, Uludağ University, Bursa, Turkey \\ ${ }^{2}$ Department of Physiology, Faculty of Veterinary Medicine Uludağ University, Bursa, Turkey \\ ${ }^{3}$ Hastavuk, Commercial Breeder Farm, Bursa, Turkey
}

(Received 9 October 2013; Accepted 15 October 2014; First published online 19 November 2014)

\begin{abstract}
Copyright resides with the authors in terms of the Creative Commons Attribution 2.5 South African Licence.
See: http://creativecommons.org/licenses/by/2.5/za

Condition of use: The user may copy, distribute, transmit and adapt the work, but must recognise the authors and the South African Journal of Animal Science.
\end{abstract}

\begin{abstract}
The objective of this study was to investigate the effect of oxygen supplementation on broiler eggs in a hatchery at high altitude on the growth performance and ascites syndrome of broilers reared at low altitude. The treatment groups were low altitude with no oxygen supplemented in the hatchery (LA-NOX); high altitude with oxygen supplementation in the hatchery (HA-OX); and high altitude with no oxygen supplemented in the hatchery (HA-NOX) group. Growth performance, heart weight, the concentrations of the hormones, $T_{3}, T_{4}, T_{3} T_{4}$, and and plasma concentrations of haematocrit, haemoglobin, glucose and parameters of ascites syndrome during the growing period were investigated. A total of 243 one-day-old broilers were used for this study. During the growing period, excluding days 7, 28 and 35, oxygen supplementation at high altitude did not affect the live weight of broilers compared with the HA-OX and HANOX groups. The cumulative feed consumption was determined to be lower in the LA-NOX group and the same in the HA-OX and HA-NOX groups on the 42nd day. Between 21 and 42 days old, the LA-NOX group had a better feed conversion ratio (FCR) than the HA-OX and HA-NOX groups. Chick weight (CW), yolk sac weight (YSW) and chick heart weight (CHW) were higher in the LA-NOX group than in the HA-OX and HANOX groups. At 42 days old, there were no differences between the groups in heart weight, right ventricle weight (RV), left ventricle and septum (LV+Sept.), total ventricle (TV) weight and the RV : TV ratio. The plasma $T_{3}$ level was lower in the LA-NOX group than in the HA-OX and HA-NOX groups and $T_{4}$ levels were higher in the HA-OX than in the others at 42 days old. The hypoxic conditions that occurred during the embryonic stage - which altered endogenous functions of prenatal chicks and affected several blood parameters, and oxygen supplementation at high altitude - improved chick quality. However, it did not improve subsequent FCR and feed consumption performance of chickens when they were reared at low altitude.
\end{abstract}

Keywords: Breeder eggs, growth, high altitude, oxygen supplementation

${ }^{\#}$ Corresponding author: bilgehan@uludag.edu.tr

\section{Introduction}

The partial pressure of oxygen $\left(\mathrm{O}_{2}\right)$ becomes lower with increasing altitude (Visschedijk, 1985) and a decrease in barometric pressure and $\mathrm{O}_{2}$ partial pressure at high altitude causes a lack of $\mathrm{O}_{2}$ (hypoxia), carbon dioxide $\left(\mathrm{CO}_{2}\right)$ (hypocapnia) and water (dehydration) in chickens (Visschedijk, 1991). Growth increases the need for $\mathrm{O}_{2}$ consumption (Beker et al., 2003), and rapidly growing broiler chickens need $\mathrm{O}_{2}$ for their high metabolic requirements (Julian et al., 1989). As the $\mathrm{O}_{2}$ level decreases with altitude, exposure to chronic hypoxia increases mortality during incubation and decreases growth as a result of adaptation (Julian, 2000; Villamor et al., 2004). The hypoxic condition during incubation decreases chick weight (Dzialowski et al., 2002; Sharma et al., 2006; Zhang et al., 2008). However, Bahadoran et al. (2010) found that bodyweight of newly hatched chicks from a high-altitude incubator was significantly higher than that of chicks incubated in a low-altitude one. Additionally, Giussani et al. (2007) showed that $\mathrm{O}_{2}$ supplemention of eggs incubated at sea-level could prevent high-altitude induced growth restriction completely. However, Çelen et al. (2009) found no positive impact of additional $\mathrm{O}_{2}$ supplementation at high altitude during the incubation period on weight of chicks from 31 and 55 weeks of age in broiler breeders. Meshew (1949) found that $\mathrm{O}_{2}$ 
supplementation to the hatchery at high altitude resulted in a slightly higher hatching weight of chicks and turkeys than no supplemented incubation.

Previous studies suggested that $\mathrm{O}_{2}$ and $\mathrm{CO}_{2}$ exchanges are important for embryonic development during incubation and especially for chick embryo survival (Tona et al., 2005; Altan et al., 2006; Şahan et al., 2011). At high altitude, chronic hypoxia is a more serious problem during incubation, because it affects chick embryo survival and hatchability, and has detrimental consequences for bodyweight and post-hatch bird performance (Decuypere et al., 2001; Chan \& Burggren, 2005).

This could be because of decreased efficiency in foetal resource uptake from the yolk sac, which is converted to embryonic tissues, thus making it unusable (Esmail, 2012). The importance of the yolk sac is not restricted to the life of the embryo in avian species, but extends to post-hatch life (Romanoff, 1960). Inefficient foetal resource uptake from the yolk sac increases the incidence of ascites, which has become of increasing concern (Silva et al., 1988), because of its association with increased mortality and decreased weight gain (Julian, 1993). Oxygen concentration plays a major role in the onset of ascites; reduction in atmospheric $\mathrm{O}_{2}$ concentration effectively induces ascites. It is therefore important to keep the $\mathrm{O}_{2}$ concentration above $19.6 \%$ to minimize ascites-related anomalies and maximize performance (Beker et al., 2003). Fast-growing chicken breeds are more likely to suffer from ascites because of their rapid growth and high metabolic rate, both of which require more $\mathrm{O}_{2}$ (Acar et al., 1995). The peak of ascites incidence occurs during weeks 5 to 6 of the growing period (Coleman \& Coleman, 1991).

A higher metabolic rate is associated with increased secretion of the hormones, thyroxine $\left(T_{4}\right)$ and triiodothyronine $\left(T_{3}\right)$, which are important growth promoters in chickens (Gonzales et al., 1999; Yahav, 2000; Luger et al., 2001). Thyroid hormones regulate the metabolic rate during the post-hatch period (Gabarrou et al., 1997; Decuypere et al., 2000) and are linked with ascites susceptibility (Hassanzadeh et al., 2004; De Smit et al., 2005). This becomes even more apparent under adverse environmental conditions, such as high altitude (Hassanzadeh et al., 2004).

Before a bird exhibits gross ascites syndrome lesions, commonly the right ventricle to total ventricle (RV : TV) ratio, changes in the concentrations of haemoglobin (Hb), haematocrit (PCV) (Yersin et al., 1992; Yahav et al., 1997; Wideman et al., 1998), glucose in the liver (Diaz-Cruz et al., 1996), blood gases and other parameter changes can be detected (Huchzermeyer \& DeRuyck, 1986; Maxwell et al., 1986; 1987). It is generally accepted that the greater right ventricle to total ventricle ratio (RV : TV) $(0.29 \mathrm{vs} .0 .20)$ is an indication of ascites (Julian, 1993; Owen et al., 1995; Wideman, 2001).

In previous research, Şahan et al. (2011) demonstrated that $\mathrm{O}_{2}$ supplementation at high altitude during the late incubation period of broiler eggs increased hatchability and embryonic survival rates because of decreased hypoxic stress. In this study, the aim was therefore to investigate the effect of high-altitude $\mathrm{O}_{2}$ supplementation on growth performance and ascites susceptibility of broiler chicks reared at low altitude.

\section{Material and Methods}

The housing and experimental procedures reported in this experiment were carried out according to the Institutional Animal Care and Use Committee of Uludag University of Bursa, Turkey. During the experiment, all researchers had valid animal care and use certificates. The fertile eggs were obtained from a commercial broiler breeder parent stock (Ross 308) at 50 weeks old, and reared at low altitude (100 m). The experimental details of incubation period in this study followed the method described by Şahan et al. (2011).

At hatch, 243 chicks from each treatment group were randomly selected, and weighed for the second part of the trial. Chicks from each treatment group were randomly divided over three floor pens (27 chicks per pen, each with three replicates) and reared on a low-altitude farm (100 m above sea level). The same trial groups - LA-NOX (low altitude with non-oxygen supplemented in the hatchery), HA-NOX (high altitude with non- $\mathrm{O}_{2}$ supplemented in the hatchery) and HA-OX (high altitude with $\mathrm{O}_{2}$ supplemented in the hatchery) - were used. Wood shavings were used as litter material, and spread to the depth of $7-8 \mathrm{~cm}$ on the floor. At placement, ten 1-day-old chicks were randomly selected from each treatment group (a total of 30), weighed and killed by decapitation. The heart, liver and yolk sac were removed and weighed with a digital scale with \pm $0.1 \mathrm{~g}$ precision for chick weight (CW), heart weight (CHW), yolk sac weight (YSW) and liver weight (LW).

The chicks were reared under a continuous lighting programme, $24 \mathrm{~h}$ light from day 1 to day 5 , followed by $23 \mathrm{~h}$ light and $1 \mathrm{~h}$ darkness for the remainder of the trial period. The feeding programme consisted of a commercial standard broiler starter diet $(220 \mathrm{~g} \mathrm{CP} / \mathrm{kg}$ and $12.8 \mathrm{MJ} \mathrm{ME} / \mathrm{kg}$ ) fed from day 1 to 14 , a grower diet $(220 \mathrm{~g} \mathrm{CP} / \mathrm{kg}$ and $13.3 \mathrm{MJ} \mathrm{ME} / \mathrm{kg})$ fed from day 15 to 28 , and a finisher diet $(210 \mathrm{~g} \mathrm{CP} / \mathrm{kg}$ and $13.5 \mathrm{MJ} \mathrm{ME} / \mathrm{kg}$ ) fed from days 29 to 42 . Feed and water were provided ad libitum. Individual live weight and feed consumption values were recorded and cumulative feed consumption and feed conversion ratio (FCR) were calculated every week for each pen. Mortality was recorded daily. All dead birds were examined for heart failure and ascites lesions, as determined in previous publications (Julian et al., 1989; Julian, 1993). 
At the end of the trial, at 42 days of age, 11 broilers were randomly selected from each treatment group and killed by decapitation. The hearts were removed and dissected to obtain heart weights for calculating the right ventricle (RV), total ventricle weights (TV) as well as the RV : TV ratio. The heart weight, right and total ventricles were weighed on a digital scale with $\pm 0.1 \mathrm{~g}$ precision.

At days 1, 7, 21 and 42, approximately $1 \mathrm{~mL}$ blood samples were collected randomly from 15 broilers per treatment group via cardiac puncture into lithium heparinized tubes on ice to separate plasma and determine plasma thyroid hormone $\left(\mathrm{T}_{3}, \mathrm{~T}_{4}, \mathrm{~T}_{3 / 4}\right), \mathrm{PCV}, \mathrm{Hb}$ and glucose concentrations. The PCV concentration was determined by centrifuging the blood in heparinized capillary tubes in a micro capillary centrifuge (Nuve Laboratory Equipment, Ankara, Turkey) for $5 \mathrm{~min}$ at $13000 \times g$ and visualized on a reader (International Equipment Co., Needham, Mass, USA). The Hb concentration was analysed colorimetrically with a Biolabo Reagents diagnostic kit (Biolabo Sa, Maizy, France) according to the manufacturer's instructions. After centrifugation (Hettich EBA 21 Centrifuge, GMI Inc., Minnesota, USA) at $3000 \times g$ for 10 min the cellular fraction was separated from the plasma. The plasma was stored at $-20^{\circ} \mathrm{C}$ until it was analysed by radioimmunoassay (Davis et al., 2000). The $T_{3}$ assay was characterized by intra-assay and inter-assay variations (CV) of $2.11 \%$ and $3.15 \%$, respectively. The $\mathrm{T}_{4}$ assay was characterized by intra-assay and inter-assay CV of $1.96 \%$ and $4.10 \%$, respectively. The blood glucose was determined by the glucose oxidase method (Sigma Chemical Co.). Chicks were reared under a continuous lighting programme, $24 \mathrm{~h}$ light from day 1 to 5 , followed by $23 \mathrm{~h}$ light and $1 \mathrm{~h}$ darkness for the remainder of the trial period.

The data were subjected to one-way analysis of variance (ANOVA) using the general linear models procedure in SAS (2007). The analysis for the percentage data of PCV was conducted after arcsine transformation. Significant differences between the treatment means were determined by Duncan's multiple range test. A probability of $P<0.05$ was considered significant.

\section{Results}

Bird live weight, weekly basis feed consumption, cumulative feed consumption and feed conversion values of the low altitude (LA-NOX), high altitude (HA-NOX) and high altitude with $\mathrm{O}_{2}$ supplemented (HA-OX) groups are given in Table 1. From the 14th to 28th day of age, live weights were higher in the LA-NOX group than the high altitude groups $(P<0.01)$ while there was no significant difference at 7 days old $(P>0.05)$. Also, at days 35 and $42, \mathrm{O}_{2}$ supplementation at a high altitude did not affect the live weight of broilers compared with the HA-OX and HA-NOX groups.

In this study, weekly basis feed consumption was found to be significant on the 28th, 35th and 42nd days $(P<0.01)$. Oxygen supplementation at high altitude affected the weekly basis feed consumption, and the LA-NOX and HA-OX groups were found to be similar at the 28th and 35th days. The lowest weekly basis feed consumption was found in the LA-NOX group on the 42nd day $(P<0.01)$. The cumulative feed consumption was determined to be lower in the LA-NOX group and the same in the HA-OX and HA-NOX groups on the 42 nd day $(P<0.05)$. The FCR was affected by altitude. Between 21 and 42 days old, the LA-NOX group had a better FCR compared with the HA-OX and HA-NOX groups $(P<0.01)$. The FCR was the same in both HA-OX and HA-NOX groups at the 21st, 28th, 35th and 42nd days of age.

The chick body and organ weight values and mortality rate of the LA-NOX, HA-NOX and HA-OX groups are given in Table 2. The CW $(P<0.01)$, YSW $(P<0.05)$ and CHW $(P<0.01)$ were higher in the LANOX group than the HA-OX and HA-NOX groups. At 42 days old, there were no differences in heart weight, $\mathrm{RV}, \mathrm{LV}+$ Sept., TV weight and the RV : TV ratio between the groups $(P>0.05)$. In the present study, total mortality during to growing period did not differ between the groups. A mortality ratio because of ascites was not observed in the groups. However, during the growing period, two mortalities were observed in HA-NOX group (Table 2).

The thyroid hormones and blood parameters of the broilers of the LA-NOX, HA-OX and HA-NOX groups are given in Table 3. The lowest ratio of $\mathrm{T}_{3}: \mathrm{T}_{4}$ value was found in the LA-NOX group $(P<0.01)$. The plasma $\mathrm{T}_{4}$ level did not differ between groups $(P>0.05)$. Chick blood PCV value was lower in the LA-NOX group than in the high-altitude groups $(P<0.01)$. The highest one-day-old chick blood $\mathrm{Hb}$ value was found in the HA-NOX group compared with the HA-OX and LA-NOX groups $(P<0.01)$. The glucose level did not differ between groups $(P>0.05)$ in one-day-old chicks. However, there were differences in blood glucose level, and the highest blood glucose level was found in the HA-OX group at 7 and 21 days old $(P<0.01)$. The plasma $T_{3}$ level was lower in the LA-NOX group than the HA-OX and HA-NOX groups and $\mathrm{T}_{4}$ levels were higher in the HA-OX than the others at 42 days old $(P<0.01)$. The highest PCV value was found in the LANOX group at 42 days old $(P<0.05)$. 
Table 1 Broiler live weight, weekly basis feed consumption, cumulative feed consumption and feed conversion values of groups (mean \pm SEM)

\begin{tabular}{|c|c|c|c|c|c|c|c|c|}
\hline \multirow{2}{*}{ Variables } & \multirow{2}{*}{ Treatment } & \multicolumn{7}{|c|}{ Age (day) } \\
\hline & & Day 1 & Day 7 & Day 14 & Day 21 & Day 28 & Day 35 & Day 42 \\
\hline \multirow{4}{*}{ Live weight, g } & & $\star *$ & NS & $\star \star$ & $* *$ & $\star *$ & * & * \\
\hline & LA-NOX & $42.9^{a} \pm 0.55$ & $145.7 \pm 2.57$ & $340.8^{a} \pm 0.89$ & $702.0^{a} \pm 5.45$ & $1242^{a} \pm 5.17$ & $1832^{\mathrm{a}} \pm 15.50$ & $2420^{a} \pm 3.32$ \\
\hline & HA-OX & $40.8^{b} \pm 0.33$ & $140.3 \pm 0.74$ & $325.8^{\mathrm{b}} \pm 1.58$ & $636.1^{\mathrm{b}} \pm 12.02$ & $1148^{\mathrm{b}} \pm 18.86$ & $1657^{b} \pm 55.81$ & $2269^{b} \pm 45.22$ \\
\hline & HA-NOX & $40.9^{b} \pm 1.18$ & $140.4 \pm 4.54$ & $331.6^{b} \pm 2.89$ & $649.5^{b} \pm 5.10$ & $1196^{\mathrm{ab}} \pm 0.47$ & $1720^{\mathrm{ab}} \pm 40.18$ & $2285^{b} \pm 29.53$ \\
\hline \multirow{4}{*}{$\begin{array}{l}\text { Weekly basis } \\
\text { feed } \\
\text { consumption, g }\end{array}$} & & & NS & NS & NS & ** & $\star *$ & $\star \star$ \\
\hline & LA-NOX & - & $159.7 \pm 0.86$ & $240.4 \pm 0.18$ & $398.5 \pm 5.33$ & $948.5^{b} \pm 19.67$ & $837.4^{b} \pm 19.67$ & $1306.3^{\mathrm{b}} \pm 2.99$ \\
\hline & HA-OX & - & $152.6 \pm 2.28$ & $240.7 \pm 1.06$ & $448.5 \pm 17.12$ & $949.4^{\mathrm{b}} \pm 11.01$ & $838.3^{\mathrm{b}} \pm 11.012$ & $1428.0^{a} \pm 3.10$ \\
\hline & HA-NOX & - & $154.6 \pm 1.65$ & $238.9 \pm 1.07$ & $413.0 \pm 18.38$ & $1034.0^{a} \pm 4.64$ & $918.4^{a} \pm 2.073$ & $1422.0^{a} \pm 13.36$ \\
\hline \multirow{4}{*}{$\begin{array}{l}\text { Cumulative feed } \\
\text { consumption, } g\end{array}$} & & & & NS & NS & * & $\star$ & $*$ \\
\hline & LA-NOX & - & - & $399.5 \pm 0.18$ & $798.0 \pm 5.16$ & $1747^{b} \pm 14.44$ & $2584^{b} \pm 34.19$ & $3890.7^{b} \pm 31.20$ \\
\hline & HA-OX & - & - & $395.1 \pm 2.54$ & $843.6 \pm 14.58$ & $1793^{\mathrm{ab}} \pm 25.60$ & $2631^{\mathrm{b}} \pm 36.61$ & $4059.0^{a} \pm 33.51$ \\
\hline & HA-NOX & - & - & $394.4 \pm 0.32$ & $807.4 \pm 18.70$ & $1841^{a} \pm 14.06$ & $2760^{\mathrm{a}} \pm 11.99$ & $4006.0^{a} \pm 20.83$ \\
\hline \multirow{4}{*}{$\begin{array}{l}\text { Feed conversion } \\
\text { ratio, } g / g\end{array}$} & & & NS & NS & $\star \star$ & $\star \star$ & $\star \star$ & $\star \star *$ \\
\hline & LA-NOX & - & $1.09 \pm 0.026$ & $1.18 \pm 0.003$ & $1.14^{\mathrm{b}} \pm 0.017$ & $1.41^{\mathrm{b}} \pm 0.006$ & $1.41^{b} \pm 0.029$ & $1.61^{b} \pm 0.012$ \\
\hline & HA-OX & - & $1.08 \pm 0.023$ & $1.21 \pm 0.011$ & $1.32^{\mathrm{a}} \pm 0.002$ & $1.56^{\mathrm{a}} \pm 0.003$ & $1.60^{\mathrm{a}} \pm 0.032$ & $1.79^{\mathrm{a}} \pm 0.023$ \\
\hline & HA-NOX & - & $1.10 \pm 0.049$ & $1.19 \pm 0.010$ & $1.25^{\mathrm{a}} \pm 0.020$ & $1.54^{\mathrm{a}} \pm 0.011$ & $1.61^{a} \pm 0.031$ & $1.76^{a} \pm 0.015$ \\
\hline
\end{tabular}

a,b Within columns, within variables, means with different superscripts are significantly different at ${ }^{\star \star} P<0.01$ and ${ }^{*} P<0.05$; NS: not significant.

LA-NOX: Iow altitude, HA-OX: high altitude with oxygen supplemented, HA-NOX: high altitude with non-oxygen supplemented;

$\mathrm{n}: 81$ chicks were used for each treatment group (total 243 chicks). 
Table 2 Chick and organ weight values and mortality rate of groups (mean \pm SEM)

\begin{tabular}{|c|c|c|c|c|c|}
\hline Body part values & $\mathbf{n}$ & LA-NOX & HA-OX & HA-NOX & $P$ \\
\hline \multicolumn{6}{|l|}{$1 \mathrm{~d}$ old broiler } \\
\hline CW, g & 10 & $43.55^{\mathrm{a}} \pm 1.47$ & $40.04^{b} \pm 1.14$ & $40.37^{\mathrm{b}} \pm 1.41$ & ** \\
\hline YSW, g & 10 & $4.59^{\mathrm{a}} \pm 1.38$ & $3.40^{\mathrm{b}} \pm 0.94$ & $3.96^{\mathrm{b}} \pm 0.59$ & * \\
\hline LW, g & 10 & $1.18 \pm 0.13$ & $1.16 \pm 0.07$ & $1.25 \pm 0.08$ & NS \\
\hline CHW, g & 10 & $0.39^{a} \pm 0.01$ & $0.35^{\mathrm{b}} \pm 0.01$ & $0.34^{b} \pm 0.01$ & $\star \star$ \\
\hline \multicolumn{6}{|l|}{$42 \mathrm{~d}$ old broiler } \\
\hline Heart weight, g & 11 & $8.07 \pm 0.29$ & $7.41 \pm 0.42$ & $7.40 \pm 0.46$ & NS \\
\hline Right ventricle (RV), g & 11 & $1.03 \pm 0.04$ & $0.92 \pm 0.05$ & $1.02 \pm 0.08$ & NS \\
\hline Left ventricle(LV) +Sept., g & 11 & $5.87 \pm 0.19$ & $5.01 \pm 0.22$ & $5.53 \pm 0.38$ & NS \\
\hline Total ventricle (TV), g & 11 & $6.90 \pm 0.21$ & $5.92 \pm 0.26$ & $6.56 \pm 0.45$ & NS \\
\hline $\mathrm{RV}: \mathrm{TV}$ & 11 & $0.15 \pm 0.01$ & $0.15 \pm 0.01$ & $0.16 \pm 0.00$ & NS \\
\hline Mortality rate & & - & & $2 / 81$ & \\
\hline
\end{tabular}

${ }^{\mathrm{a}, \mathrm{b}}$ Means within rows with no common superscript are significantly differ at $P<0.01^{\star \star}$ and $P<0.05^{\star}$. NS: not significant.

LA-NOX: low altitude; HA-OX: high altitude with oxygen supplemented; HA-NOX: high altitude with non-oxygen supplemented; CW: chick weight; CHW: chick heart weight; YSW: yolk sac weight; LW: liver weight.

\section{Discussion}

Depending on the higher incidence of ascites, high-altitude incubated chickens had a different growth pattern during their post-hatch growing period and reached their maximum growth at 6 weeks old (Bahadoran et al., 2010). In the present study, from 14 to 42 days old, live weights were higher in the LA-NOX group than in the high altitude group. The $\mathrm{O}_{2}$ supplementation at high altitude did not affect the live weight of broilers compared with the HA group except at days 7, 28 and 35 . The results of the present study are in contrast with those of Hassanzadeh et al. (2004), Bahadoran et al. (2010) and Çelen et al. (2009), who showed that high-altitude incubated chickens had significantly higher bodyweights than low-altitude incubated chickens at 42 days old. In contrast to our findings, Meshew (1949) and Wilgus \& Sadler (1954) report a slightly heavier weight at 2 and 3 weeks old when $\mathrm{O}_{2}$ was added.

The lipid uptake from the yolk sac between day 22 and hatch was greater in embryos from the faster growing line (Ding et al., 1995). The yolk sac played a critical role in growth of broiler chicks during the first week of age; thereafter the chicks compensated for bodyweight gain (Ali et al., 2007). Similarly, Bhanja et al. (2009) found that faster utilization of yolk sac resulted in better weight gain of broilers at 5 weeks old. In the present study, the yolk sac weight was found to be lower in the HA groups than the LA-NOX group, and, in contrast to Bhanja et al. (2009), at the end of the growing period, the LA-NOX group had higher live weights than the HA groups.

Some researchers have suggested that extra $\mathrm{O}_{2}$ supplementation during high-altitude incubation improves body weight, feed consumption and FCR (Beker et al., 2003; Quintana et al., 2006; Çelen et al., 2009) in 42-day-old broilers reared at low altitude. However, in the present study, at the end of the growing period, feed consumption and FCR were lower in the LA-NOX group than the HA ones. However, $\mathrm{O}_{2}$ supplementation at high altitude did not affect feed consumption and FCR. In contrast to our findings, Hassanzadeh et al. (2004) and Bahadoran et al. (2010) found that there were no differences between the feed intakes of the high-altitude and low-altitude incubated groups during the growing period, and FCR was found to be lower in the high-altitude incubated group than low-altitude incubated group.

In the present study, altitude affected $\mathrm{CHW}$. However, the $\mathrm{O}_{2}$ supplementation at high altitude did not affect heart weight. These findings agree with past research (Richards et al., 1991; Christensen et al., 1997). For rapid growth a broiler makes blockades in supply organs such as the liver and the gastrointestinal tract after hatching (Katanbaf et al., 1988). In the present study, altitude affected the chick yolk sac weight; though $\mathrm{O}_{2}$ supplementation at high altitude did not affect it. Neither altitude nor $\mathrm{O}_{2}$ supplementation affected chick liver weight. 
Table 3 Thyroid hormones and blood parameters of broilers at low altitude, high altitude and high altitude in oxygen supplemented groups at different periods (mean \pm SEM)

\begin{tabular}{|c|c|c|c|c|c|}
\hline Broilers & & LA-NOX & HA-OX & HA-NOX & $P$ \\
\hline $1 \mathrm{~d}$ old broiler & $\mathrm{n}$ & & & & \\
\hline Plasma $T_{3}, n g / m L$ & 15 & $0.75^{\mathrm{b}} \pm 0.17$ & $0.85^{a b} \pm 0.12$ & $0.97^{\mathrm{a}} \pm 0.14$ & ** \\
\hline Plasma $T_{4}, \mathrm{ng} / \mathrm{mL}$ & 15 & $10.05 \pm 0.92$ & $9.82 \pm 0.89$ & $9.15 \pm 1.34$ & NS \\
\hline Plasma $T_{3} / T_{4}$ & 15 & $0.07^{c} \pm 0.02$ & $0.09^{b} \pm 0.01$ & $0.11^{\mathrm{a}} \pm 0.01$ & ** \\
\hline PCV (haematocrit), \% & 15 & $27.45^{\mathrm{b}} \pm 0.51$ & $32.50^{\mathrm{a}} \pm 1.00$ & $30.82^{a} \pm 1.00$ & ** \\
\hline $\mathrm{Hb}$ (haemoglobin), g/dL & 15 & $8.96^{b} \pm 0.70$ & $8.17^{b} \pm 0.21$ & $11.63^{\mathrm{a}} \pm 0.22$ & ** \\
\hline Glucose, mg/dL & 15 & $268.30 \pm 6.07$ & $256.40 \pm 4.77$ & $273.90 \pm 6.62$ & NS \\
\hline \multicolumn{6}{|l|}{$7 \mathrm{~d}$ old broiler } \\
\hline Plasma $T_{3}, \mathrm{ng} / \mathrm{mL}$ & 15 & $3.40 \pm 0.12$ & $3.15 \pm 0.10$ & $3.24 \pm 0.11$ & NS \\
\hline Plasma $T_{4}, \mathrm{ng} / \mathrm{mL}$ & 15 & $7.23 \pm 0.39$ & $6.57 \pm 0.25$ & $7.39 \pm 0.35$ & NS \\
\hline Plasma $T_{3} / T_{4}$ & 15 & $0.50 \pm 0.04$ & $0.49 \pm 0.03$ & $0.45 \pm 0.03$ & NS \\
\hline PCV (haematocrit), \% & 15 & $25.33 \pm 0.50$ & $25.20 \pm 0.40$ & $26.07 \pm 0.76$ & NS \\
\hline $\mathrm{Hb}$ (haemoglobin), g/dL & 15 & $6.67 \pm 0.18$ & $6.16 \pm 0.19$ & $6.57 \pm 0.21$ & NS \\
\hline Glucose, mg/dL & 15 & $250.1^{b} \pm 7.13$ & $315.6^{a} \pm 15.64$ & $254.9^{b} \pm 6.70$ & ** \\
\hline \multicolumn{6}{|l|}{$21 \mathrm{~d}$ old broiler } \\
\hline 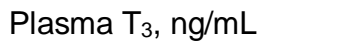 & 15 & $2.51 \pm 0.08$ & $2.82 \pm 0.06$ & $2.70 \pm 0.13$ & NS \\
\hline Plasma $T_{4}, n g / m L$ & 15 & $8.39 \pm 0.52$ & $7.93 \pm 0.50$ & $8.57 \pm 0.38$ & NS \\
\hline Plasma $T_{3} / T_{4}$ & 15 & $0.32 \pm 0.02$ & $0.38 \pm 0.03$ & $0.33 \pm 0.02$ & NS \\
\hline PCV (haematocrit), \% & 15 & $28.20 \pm 0.60$ & $27.53 \pm 0.43$ & $28.40 \pm 0.42$ & NS \\
\hline $\mathrm{Hb}$ (haemoglobin), g/dL & 15 & $7.05^{b} \pm 0.26$ & $7.87^{\mathrm{ab}} \pm 0.13$ & $8.64^{a} \pm 0.65$ & * \\
\hline Glucose, mg/dL & 15 & $249.0^{\mathrm{b}} \pm 3.40$ & $268.9^{a} \pm 5.15$ & $253.3^{b} \pm 3.59$ & $\star \star$ \\
\hline \multicolumn{6}{|l|}{$42 \mathrm{~d}$ old broiler } \\
\hline Plasma $T_{3}, n g / m L$ & 15 & $0.39 \pm 0.02$ & $0.71^{a} \pm 0.03$ & $0.65^{a} \pm 0.08$ & ** \\
\hline Plasma $T_{4}, \mathrm{ng} / \mathrm{mL}$ & 15 & $12.61^{b} \pm 0.63$ & $17.05^{\mathrm{a}} \pm 0.56$ & $13.45^{\mathrm{b}} \pm 0.40$ & ** \\
\hline Plasma $\mathrm{T}_{3} / \mathrm{T}_{4}$ & 15 & $0.04 \pm 0.00$ & $0.05 \pm 0.00$ & $0.05 \pm 0.00$ & NS \\
\hline PCV (haematocrit), \% & 15 & $30.20^{\mathrm{a}} \pm 0.40$ & $29.73^{\mathrm{ab}} \pm 0.30$ & $28.33^{b} \pm 0.59$ & * \\
\hline $\mathrm{Hb}$ (haemoglobin), g/dL & 15 & $6.47 \pm 0.14$ & $6.73 \pm 0.08$ & $6.29 \pm 0.17$ & NS \\
\hline Glucose, mg/dL & 15 & $194.1 \pm 5.52$ & $215.8 \pm 5.67$ & $194.8 \pm 6.39$ & NS \\
\hline
\end{tabular}

${ }^{a, b, c}$ Means within the same row with no common superscript are significantly different at $P<0.01^{\star \star}$ and $P<0.05^{\star}$. NS: not significant.

LA-NOX: low altitude; HA-OX: high altitude with oxygen supplemented; HA-NOX: high altitude with non oxygen supplemented;

$\mathrm{n}$ : number of broiler.

The RV : TV, haemoglobin, hematocrit, blood gases and specific clinical chemistries can be used to determine the ascites status of a bird before gross lesions are apparent (Huchzermeyer \& DeRuyck, 1986). In the present study, neither altitude nor $\mathrm{O}_{2}$ supplementation affected the heart weight, RV, LV+Sept., TV weight or the RV : TV ratio at 42 days old. The highest RV : TV ratio found was 0.16 , which is lower than what is considered an indicator for ascites development (Julian, 1993; Wideman, 2001). The RV : TV ratio had been clarified for broilers previously (Julian et al., 1989; Julian, 1993) and a healthy broiler should have an RV : TV ratio lower than 0.25 , but is at risk if this value is greater than 0.29 . Mortality because of the ascites syndrome was not observed in our groups. Numerically, two mortalities were observed in the HANOX group. In contrast to our findings, Bahadoran et al. (2010) found that high-altitude incubated chickens indicated lower RV hypertrophy and greater ascites mortality than low-altitude incubated chickens during the 
growing period at high altitude. Similar to our findings, there was no mortality difference in low-altitude reared groups incubated at low or high altitude (Hassanzadeh et al., 2004).

Thyroid hormones are important for regulating the metabolic rate during the post-hatch period (Decuypere et al., 2000; Lin et al., 2008) and are linked with ascites susceptibility in broiler chickens' later life (Hassanzadeh et al., 2004; De Smit et al., 2005). This becomes even more apparent under adverse environmental conditions, such as high altitude (Hassanzadeh et al., 1999; 2004). At high altitude, there is an increase in the blood viscosity accompanied by an increased haematocrit together with pulmonary vasoconstriction (Julian, 1993). In the present study, altitude affected the one-day-old chick plasma $\mathrm{T}_{3}$ level, $\mathrm{T}_{3}: \mathrm{T}_{4}$, haematocrit $(P C V)$ and haemoglobin $(\mathrm{Hb})$ values, and $\mathrm{O}_{2}$ supplementation affected the $\mathrm{T}_{3}: \mathrm{T}_{4}$ and $\mathrm{Hb}$ values. The observed blood plasma $\mathrm{Hb}$ in this study is in agreement with findings by Bagley \& Christensen (1991), but is in contrast with Hassanzadeh et al. (2004) for plasma $T_{3}, T_{4}$ and $T_{3}: T_{4}$ levels. Similarly, in agreement with Christensen et al. (1997), $\mathrm{O}_{2}$ supplementation during incubation did not affect blood glucose concentration of hatched chicks. The PCV value is a reflection of physiological $\mathrm{O}_{2}$ transport capacity (Ippek \& Şahan 2006). However, Luger et al. (2001) suggested that hematocrit and thyroid hormones could provide a good indication of ascites development but only during the last week of life and not in all cases. None of these parameters, however, can predict the development of ascites at an early age. In the present study, during the growing period at low altitude, the highest blood glucose level was found in the HA-OX group at 7 and 21 days old and the lowest plasma $T_{3}$ and $T_{4}$ levels and highest PCV values were found in the LA-NOX group at 42 days old. However, some researchers have suggested that there is not always an association between ascites syndrome and the haematocrit values (Shlosberg et al., 1998; Hassanzadeh et al., 2000; Scheele et al., 2005). As reported by Zhang et al. (2007), significant increase in the haematocrit and $\mathrm{Hb}$ values were obtained in the birds reared at high altitude compared with those birds reared at low altitude. In contrast to our results, Bahadoran et al. (2010) found that low-altitude incubated chickens showed higher haematocrit values than high altitude incubated chickens only at 7 days old, and the plasma $T_{3}$ and $T_{4}$ levels were not affected by the two altitudes during the growing period. This may be attributed to the chronic hypobaric hypoxia, which results in a pronounced increase in $\mathrm{O}_{2}$ capacity and the hematocrit ratio; hence, the $\mathrm{Hb}$ values were significantly increased in high-altitude pigeons (Maginniss et al., 1997).

Results reported here were similar to the findings of Hassanzadeh et al. (2004), who found that chicks hatched at high altitude, then grown at low altitude, showed significantly higher plasma $T_{4}$ concentrations than high-altitude grown birds. Özkan et al. (2006) found that ascitic birds had significantly higher hematocrit values than healthy birds and the plasma $T_{3}$ concentration was significantly lower in ascitic broilers than in healthy ones at 30 and 37 days old. The low $\mathrm{O}_{2}$ pressure in high-altitude incubators is an important factor that can alter the development of prenatal and postnatal chicks (Decuypere, 2002; Hassanzadeh, 2009). At high altitudes, the low partial pressure of $\mathrm{O}_{2}$ causes hypoxia with lower lung activity and higher arterial pressure and affects growth rates (Esmail, 2012).

\section{Conclusions}

The hypoxic conditions during the hatching period affected several blood parameters, such as plasma $T_{3}$, plasma $T_{3} / T_{4}$ and $\mathrm{Hb}$ levels, in one-day-old chicks. At high altitude, the supplemental $\mathrm{O}_{2}$ during the hatching period improved chick quality, but did not improve the subsequent FCR and feed consumption performance of chickens when they were reared at low altitude. Better growth and feed consumption performance was observed for the broiler chicks that were hatched and reared at low altitude. The results of the current study add to the broiler producers' knowledge base and contribute to the scientific literature, and may help to clarify the effects of high altitude and $\mathrm{O}_{2}$ supplemantation during hatching on the growth performance of broiler chicks, because many broiler producers obtain their chicks from high-altitude hatcheries and rear them at many altitudes.

\section{Acknowledgements}

We would like to thank the directors of the commercial breeder farm Hastavuk, who provided the facilities for this study. This study was supported financially by the Scientific Research Project Council of Uludag University (Project Number: Z2008/21). This manuscript was edited by American journal experts.

\section{References}

Acar, N., Sizemore, F.G., Leach, G.R., Wideman Jr., R.F., Owen, R.L. \& Barbato, G.F., 1995. Growth of broiler chickens in response to feed restriction regiments to reduce ascites. Poult. Sci. 74, 833-843.

Ali, O.H.A., Elzubeir, E.A. \& Elhadi, H.M., 2007. Effect of residual yolk sac on growth, liver total lipids and serum total lipids in broiler chicks. Pakistan J. Biol. Sci. 10, 4559-4562. 
Altan, Ö., Şahan, Ü., İpek, A., Aydin, C. \& Bayraktar, H., 2006. Effects of oxygen supplementation on embryonic survival, hematological parameters and plasma glucose level of broiler chicks. Arch. Geflügelkd. 70, 64-68.

Bagley, L.G. \& Christensen, V.L., 1991. Hatchability, hematological indices, and growth of turkey embryos incubated at high altitude with supplemented oxygen during the first and fourth weeks of incubation. Poult. Sci. 70, 358-365.

Bahadoran, S., Hassanzadeh, M. \& Zamanimoghaddam, A.K., 2010. Effect of chronic hypoxia during the early stage of incubation on prenatal and postnatal parameters related to ascites syndrome in broiler chickens. Iran. J. Vet. Res. 11, 64-71.

Bhanja, S.K., Anjali Devi, C., Panda, A.K. \& Shyam Sunder, G., 2009. Effect of post hatch feed deprivation on yolk-sac utilization and performance of young broiler chickens. Asian-Austral. J. Anim. Sci. 22, 1174-1179.

Beker, A., Vanhooser, S.L., Swartzlander, J.H. \& Teeter, R.G., 2003. Graded atmospheric oxygen level effects on performance and ascites incidence in broilers. Poult. Sci. 82, 1550-1553.

Chan, T. \& Burggren, W., 2005. Hypoxic incubation creates differential morphological effects during specific developmental critical windows in the embryo of the chicken (Gallus gallus). Resp. Physiol. Neurobi. 145, 251-263.

Christensen, V.L., Donaldson, W.E. \& Nestor, K.E., 1997. Effect of an oxygen-enriched environment on the survival of turkey embryos between twenty-five and twenty-eight days of age. Poult. Sci. 76, 1556-1562.

Çelen, M.F., Yildirim, I., Parlat, S.S. \& Alkiş, E., 2009. The effects of broiler breeder age and extra oxygen addition into incubator at high altitude $(1700 \mathrm{~m})$ on hatching results and subsequent performance in broilers. J. Anim. Vet. Adv. 8, 1438-1442.

Coleman, M.A. \& Coleman, G.E., 1991. Ascites control through proper hatchery management. Misset World Poultry 7, 33-35.

Davis, G.S., Anderson, K.G. \& Carrol, A.Q.S., 2000. The effects of long-term caging and molt of Single Comb White Leghorn hens of heterophil to lymphocyte ratios, corticosterone and thyroid hormones. Poult. Sci. 79, 514-518.

Decuypere, E., 2002. Ascites as a multifactorial syndrome of broiler chickens: considerations from a developmental and selection viewpoint. Proc. $2^{\text {nd }}$ Symposium World Poul. Sci. Assoc. Iran Branch, Tehran, Iran. pp. 119-136.

Decuypere, E., Buyse, J. \& Buys, N., 2000. Ascites in broiler chickens: exogenous and endogenous structural and functional causal factors. World Poult. Sci. J. 56, 367-377.

Decuypere, E., Tona, K., Bruggeman, V. \& Bamelis, F., 2001. The day-old chick: a crucial hinge between breeders and broiler. World Poult. Sci. J. 57, 127-138.

De Smit, L., Tona, K., Bruggeman, V., Onagbesan, O., Hassanzadeh, M., Arckens, L. \& Decuypere, E., 2005. Comparison of three lines of broilers differing in ascites susceptibility or growth rate. 2. Egg weight loss, gas pressures, embryonic heatproduction, and physiological hormone levels. Poult. Sci. 84, 1446-1452.

Diaz-Cruz, A., Nava, C., Villanueva, R., Serret, M., Guinzberg, R. \& Pina, E., 1996. Hepatic and cardiac oxidative stress and other metabolic changes in broilers with the ascites syndrome. Poult. Sci. 75, 900-903.

Ding, S.T., Nestor, K.E. \& Lilburn, M.S., 1995. The concentration of different lipid classes during late embryonic development in a randombred turkey population and a subline selected for increased body weight at sixteen weeks of age. Poult. Sci. 74, 374-382.

Dzialowski, E.M., Von Plettenberg, D., Elmonoufy, N.A. \& Burggren, W.W., 2002. Chronic hypoxia alters the physiological and morphological trajectories of developing chick- en embryos. Comp. Biochem. Physiol. A Mol. Integr. Physiol. 131, 713-724.

Esmail, S.H., 2012. Rearing chickens at high altitude. World poultry.net http://www.worldpoultry.net/Broilers/Housing/2012/5/Rearing-chickens-at-high-altitudes-WP010363W/

Gabarrou, J.F., Duchump, C., Williams, J. \& Geraert, P.A., 1997. A role of thyroid hormones in the regulation of dietinduced thermogenesis in birds. Br. J. Nutr. 78, 963-973.

Giussani, D.A., Salinas, C.E., Villena, M. \& Blanco, C.E., 2007. The role of oxygen in prenatal growth: Studies in the chick embryo. J. Physiol. 585.3, 911-917.

Gonzales, E., Buyse, J., Sartori, J.R., Loddi, M.M. \&. Decuypere, E., 1999. Metabolic disturbances in male broilers of different strains. 2. Relationship between the thyroid and somatotropic axes with growth and mortality. Poult. Sci. 78, 516-521.

Hassanzadeh, M., 2009. New approach for the incidence of ascites syndrome in broiler chickens and management control the metabolic disorders. Int. J. Poult. Sci. 8, 90-98. 
Hassanzadeh, M., Bozorgmeri, F.M., Buyse, J. \& Decuypere, E., 1999. The influence of altitude on ascites incidence, performance and metabolic parameters of broiler chickens. Proc. $12^{\text {th }}$ European Symp. Poult. Nutr. Velthoven, Holland. p. 350.

Hassanzadeh, M., Bozorgmeri, F.M., Akbari, A.R., Buyse, J. \& Decuypere, E., 2000. Effect of intermittent lighting schedules during the natural scotoperiod on T3-induced ascites in broiler chickens. Avian Pathol. 29, 433-439.

Hassanzadeh, M., Bozargmehri, F., Buyse, J., Bruggeman, V. \& Decuypere, E., 2004. Effect of chronic hypoxia during embryonic development on physiological functioning and on hatching and post hatching parameters related to ascites syndrome in broiler chickens. Avian Pathol. 33, 558-564.

Huchzermeyer, F.W. \& De Ruyck, A.M.C., 1986. Pulmonary hypertension syndrome associated with ascites in broilers. Vet. Rec. 119, 94.

İpek, A. \& Şahan, Ü., 2006. Effects of cold stress on broiler performance and ascites susceptibility. AsianAustral. J. Anim. Sci. 19, 734-738.

Julian, R.J., 1993. Ascites in poultry. Avian Pathol. 22, 419-454.

Julian, R.J., 2000. Physiological management and environmental triggers of ascites syndrome. Avian Pathol. 29, 519-527.

Julian R.J., Mcmillan, I. \& Aquinton, M., 1989. The effect of cold and dietary energy on right ventricular hypertrophy, right ventricular failure and ascites in meat type chickens. Avian Pathol. 18, 675-684.

Katanbaf, M.N., Siegel, P.B. \& Dunnington, E.A., 1988. Organ growth of selected lines of chickens and their F1 crosses to a common body weight or age. Theor. Appl. Genet. 74, 540-544.

Lin, H., Decuypere, E. \& Buyse, J., 2008. Effect of thyroid hormones on the redox balance of broiler chickens. Asian-Austral. J. Anim. Sci. 21, 794-800.

Luger, D., Shinder, D., Rzepakovsky, V., Rusal, M. \& Yahav, S., 2001. Association between weight gain, blood parameters, and thyroid hormones and the development of ascites syndrome in broiler chickens. Poult. Sci. 80, 965-971.

Maginniss, L.A., Bernstein, M.H., Deitch, M.A. \& Pinshow, B., 1997. Effects of chronic hypobaric hypoxia on blood oxygen binding in pigeons. J. Exp. Zool. 277, 293-300.

Maxwell, H.M., Robertson, G.W. \& Pence, S., 1986. Studies on ascetic syndrome in young broilers. 1. Haematology and pathology. Avian Pathol. 15, 511-524.

Maxwell, M.H., Tullet, S.G. \& Burton, F.C., 1987. Haematology and morphological changes in young broiler chicks with experimentally induced hypoxia. Res. Vet. Sci. 43, 331-338.

Meshew, M.H., 1949. The use of oxygen in the hatching of chicken and turkey eggs at high altitudes. Poult. Sci. 28, 87-97.

Owen, R.L., Wideman, R.F., Barbato, G.F., Cowen, B.S., Ford, B.C. \& Hattel, A.L., 1995. Morphometric and histologic change in the pulmonary system of broiler raised at stimulated high altitude. Avian Pathol. 24, 293-302.

Özkan, S., Plavnik, I. \& Yahav, S., 2006. Effects of early feed restriction on performance and ascites development in broiler chickens subsequently raised at low ambient temperature. J. Appl. Poult. Res. $15,9-19$.

Quintana, J., Hernandez, A., Ordaz, J. \& Ponce, G., 2006. Supply of $23.5 \%$ oxygen during incubation of broiler breeder eggs at 1,500 $\mathrm{m}$ above sea level and its impact on newborn chicks and during finishing at 42 days. Proc. $12^{\text {nd }}$ European Poultry Conf. Verona, Italy.

Richards, M.P., Stock, M.K. \& Metcalfe, J., 1991. Effects of brief hypoxia and hyperoxia on tissue trace element levels in the developing chick embryo. Magnesium Trace Elem. 10, 305-320.

Romanoff, A.L., 1960. The extraembryonic membranes in the avian embryo, structural and functional development. The MacMillan Company Publ. Ltd. New York,USA. pp.1041-1140.

Şahan, Ü., İpek, A., Yilmaz Dikmen, B., Aydin, C. \& Kederli, E., 2011. Effect of oxygen supplementation in the hatcher at high altitude on the incubation results of broiler eggs laid at low altitude. Br. Poult. Sci. 52, 388-394.

SAS, 2007. SAS (version 9.1.3) user's quide statics, SAS Institute Inc., Cary, NC, USA.

Scheele, C.W., Van Der Klis, J.D., Kwakernaak, C., Dekker, R.A., Van Middelkoop, J.H., Buyse, J. \& Decuypere, E., 2005. Ascites and venous carbon dioxide tensions in juvenile chickens of highly selected genotypes and native strains. World Poult. Sci. J. 61, 113-129.

Sharma, S.K., Lucittl, J.L., Nordman, C., Tinney, J.P., Tobita, K. \& Keller, B.B., 2006. Impact of hypoxia on early chick embryo growth and cardiovascular function. Pediatr. Res. 59, 116-120.

Shlosberg, A., Bellaiche, M., Berman, E., Perk, S., Deeb, N., Neumark, E. \& Cahaner, A., 1998. Relationship between broiler chicken hematocrit-selected parents and their progeny, with regard to hematocrit, mortality from ascites and bodyweight. Res. Vet. Sci. 64, 105-109. 
Silva, J.M.L., Dale, N. \& Luchesi, J.B., 1988. Effect of pelleted feed on the incidence of ascites in broilers reared at low altitudes. Avian Dis. 32, 376-378.

Tona, K., Onagbesan, O., Bruggeman, V., Mertens, K. \& Decuypere, E., 2005. Effects of turning duration during incubation on embryo growth, utilization of albumen, and stress regulation. Poult. Sci. 84, 315-320.

Villamor, E., Kessels, C.G.A., Ruijtenbeek, K., Van Suylen, R.J., Belik, J., De Mey, J.G.R. \& Blanco, C.E., 2004. Chronic in ovo hypoxia decreases pulmonary arterial contractile reactivity and induces biventricular cardiac enlargement in the chicken embryo. Am. J. Physiol-Reg. I. 287, R642-R651.

Visschedijk, A.H.J., 1985. Gas exchange and hatchability of chicken eggs incubated at simulated high altitude. J. Appl. Physiol. 58, 416-418.

Visschedijk, A.H.J., 1991. Incubation of eggs at high altitude. In: Avian Incubation. Ed: Tullet, S.G., Butterworth- Heinemann Ltd, London. pp. 285-256.

Wideman, R.F., 2001. Pathophysiology of heart/lung disorders: pulmonary hypertension syndrome in broiler chickens. World Poult. Sci. J. 57, 289-307.

Wideman Jr., R.F., Wing, T., Kirby, Y.K., Forman, M.F., Marson, N., Tackett, C.D. \& Ruiz-Feria, C.A., 1998. Evaluation of minimally invasive indices for predicting ascites susceptibility in three successive hatches of broilers exposed to cool temperatures. Poult. Sci. 77, 1565-1573.

Wilgus, H.S. \& Sadler, W.W., 1954. Incubation factors affecting hatchability of poultry eggs. 1. Levels of oxygen and carbon dioxide at high altitude. Poult. Sci. 33, 460-471.

Yahav, S., 2000. Relative humidity at moderate ambient temperatures: Its effect on male broiler chickens and turkeys. Br. Poult. Sci. 41, 94-100.

Yahav, S., Straschnow, A., Plavnik, I. \& Hurwitz, S., 1997. Blood system response of chickens to changes in environmental temperature. Poult. Sci. 76, 627-633.

Yersin, A.G., Huff, W., Ekubena, L.F., Elissalde, M.H., Harvey, R.B., Witzel, D.A. \&. Giror, L.E., 1992. Changes in haematological, blood gas, and serum biochemical variables in broilers during exposure to simulated high altitude. Avian Dis. 36,189-196.

Zhang, H., Wu, C.X., Chamba, Y. \& Ling, Y., 2007. Blood characteristics for high altitude adaptation in Tibetan chickens. Poult. Sci. 86,1384-1389.

Zhang, H., Wang, X.T., Chamba, Y., Ling, Y. \& Wu, C.X., 2008. Influences of hypoxia on hatching performance in chickens with different genetic adaptation to high altitude. Poult. Sci. 87, 2112-2116. 